\title{
Perioperative management of patients on direct oral anticoagulants
}

\author{
Virginie Dubois ${ }^{1 \dagger}$, Anne-Sophie Dincq ${ }^{1,2+}$, Jonathan Douxfils ${ }^{2,3}$, Brigitte Ickx ${ }^{4}$, Charles-Marc Samama ${ }^{5}$, \\ Jean-Michel Dogné ${ }^{2,3}$, Maximilien Gourdin ${ }^{1,2}$, Bernard Chatelain ${ }^{2,6}$, François Mullier, ${ }^{2,6 \dagger}$ and Sarah Lessire ${ }^{1,2^{*} \dagger}$
}

\begin{abstract}
Direct oral anticoagulants (DOACs) have been licensed worldwide for several years for various indications. Each year, 10-15\% of patients on oral anticoagulants will undergo an invasive procedure and expert groups have issued several guidelines on perioperative management in such situations. The perioperative guidelines have undergone numerous updates as clinical experience of emergency management has increased and perioperative studies including measurement of residual anticoagulant levels have been published. The high inter-patient variability of DOAC plasma levels has challenged the traditional recommendation that perioperative DOAC interruption should be based only on the elimination half-life of DOACs, especially before invasive procedures carrying a high risk of bleeding. Furthermore, recent publications have highlighted the potential danger of heparin bridging use when DOACs are stopped before an invasive procedure.

As antidotes are progressively becoming available to manage severe bleeding or urgent procedures in patients on DOACs, accurate laboratory tests have become the standard to guide their administration and their actions need to be well understood by clinicians.

This review aims to provide a systematic approach to managing patients on DOACs, based on recent updates of various perioperative guidance, and highlighting the advantages and limits of recommendations based on pharmacokinetic properties and laboratory tests.
\end{abstract}

Keywords: Anticoagulants, Perioperative period, Invasive procedures, Spinal anesthesia, Emergency care, Blood coagulation test

\section{Background}

The number of patients receiving treatment with direct oral anticoagulants (DOACs) is increasing, as clinical trials have demonstrated non-inferiority or superiority in terms of prevention and treatment of thrombo-embolic events [1-11] compared with vitamin $\mathrm{K}$ antagonists (VKAs).

Rapid onset and offset of action, short half-life and predictable anticoagulant effects without the need for routine monitoring were the key strengths on which these anticoagulants have been marketed. However, the perioperative management and monitoring of DOACs

\footnotetext{
* Correspondence: sarah.lessire@uclouvain.be

${ }^{\dagger}$ Equal contributors

'Université catholique de Louvain, CHU UCL Namur, Department of Anesthesiology, Yvoir, Belgium

${ }^{2}$ Namur Thrombosis and Hemostasis Center (NTHC), NAmur Research Institute of LIfe Sciences (NARILIS), Namur, Belgium

Full list of author information is available at the end of the article
}

has proved to be challenging, especially as antidotes were not available immediately following their introduction.

Several expert guidelines [12-14] were developed as soon as DOACs became available to help physicians manage these drugs. More recently, sub-group analyses of the phase III trials as well as results of recent clinical studies $[15,16]$ have influenced further guidelines [17-19]. Nowadays, around $10-15 \%$ of patients on DOACs will have to interrupt their anticoagulant before an invasive procedure every year [20, 21]. Furthermore, antidotes are gradually being licensed $[22,23]$. This review aims to summarize current guidance on the perioperative management of DOACs to reflect published research. The literature search was performed in PubMed using the following keywords: perioperative, anticoagulant, dabigatran, rivaroxaban, edoxaban and apixaban. Only publications in English were considered. 


\section{INDICATIONS FOR DOACs}

Dabigatran (a direct anti-IIa inhibitor), rivaroxaban and apixaban (two direct anti-Xa inhibitors) are licensed in the European Union for the prevention of venous thromboembolism (VTE) after orthopedic surgery (hip and knee arthroplasties), for the prevention of thromboembolic events due to non-valvular atrial fibrillation (NVAF), and in the treatment or secondary prophylaxis of VTE [24-26]. Rivaroxaban is also licensed in the European Union for the prevention of atherothrombotic events after acute coronary syndrome with elevated cardiac biomarkers.

Edoxaban is a direct anti-Xa inhibitor that has recently been licensed in the European Union for the prevention of thromboembolic events due to NVAF and the treatment or secondary prophylaxis of venous thromboembolism only [27].

These anticoagulants are given at fixed doses and do not require repetitive coagulation monitoring in the routine follow-up of patients. Table 1 summarizes the pharmacokinetic properties of DOACs. Clinical features such as advanced age, decreased creatinine clearance $(\mathrm{CrCl})$ and some drug-drug interactions are indications for using lower DOAC doses in patients at risk of having supratherapeutic anticoagulant levels at normal doses [24-27].

\section{PERIOPERATIVE MANAGEMENT OF DOACs}

Recent publications strongly recommend the development of institutional guidelines and hospital policies for the perioperative management of DOACs [17, 18]. A checklist including all aspects of the particular procedure and the patient characteristics that may increase the risks of bleeding or thrombosis should be available to guide the perioperative use of DOACs.

Table 2 shows items to consider in a perioperative checklist.

\section{The thrombo-embolic risk of the patient \\ CHADS2 or CHA2DS2-VASC score}

The CHADS2 score and the CHA2DS2-VASc score are used to predict AF-related thromboembolic risk in the absence of anticoagulation and to determine anticoagulant therapy $[28,29]$. The CHA2DS2-VASc score has shown better discrimination of patients at truly low risk of thrombo-embolism (TE) [30]. Patients with chronic AF have twice the risk of postoperative stroke than patients without AF [31]. Currently, these scores are proposed to identify patients with AF at high TE risk in a perioperative setting, when they have more than 4 individual risk factors for stroke $[19,32,33]$. However, only the individual risk factors from the CHADS2 stroke risk index were assessed in stratifying the risk of postoperative stroke and not the global value of both scores. Therefore the utility of the CHADS2 and CHA2DS2-VASc scores to predict perioperative stroke needs to be prospectively validated [34].

Table 1 Pharmacokinetic properties of direct oral anticoagulants

\begin{tabular}{|c|c|c|c|c|}
\hline & Dabigatran & Rivaroxaban & Apixaban & Edoxaban \\
\hline Target & Factor Ila & Factor Xa & Factor Xa & Factor Xa \\
\hline Prodrug & Yes & No & No & No \\
\hline $\operatorname{Tmax}(h)$ & $1.0-3.0$ & $2.0-4.0$ & $3.0-4.0$ & $1.0-2.0$ \\
\hline Half-life (h) & $12-17 \mathrm{~h}$ & $\begin{array}{l}\text { 5-9: healthy individuals } \\
\text { 11-13: elderly }\end{array}$ & 8-15: healthy individuals & $10-14$ \\
\hline Bioavailability & $\begin{array}{l}3-7 \% \\
\mathrm{pH} \text { sensitive }\end{array}$ & $\begin{array}{l}\text { For } 2.5 \mathrm{mg} \text { and } 10 \mathrm{mg}: 80-100 \% \\
\text { (fasting or fed) } \\
\text { For } 15-20 \mathrm{mg}: \\
66 \% \text { : (fasting) } \\
\text { almost } 100 \% \text { (fed) }\end{array}$ & $\pm 50 \%$ & $62 \%$ \\
\hline Metabolism & Conjugation & $\begin{array}{l}\text { CYP-dependent and independent } \\
\text { mechanism }\end{array}$ & $\begin{array}{l}\text { CYP-dependent } \\
\text { mechanism (25\%) }\end{array}$ & $\begin{array}{l}\text { CYP-dependent }(<5 \%) \\
\text { and independent } \\
\text { mechanism }(<10 \%)\end{array}$ \\
\hline Active metabolites & Yes - acylglucuronides & No & No & Yes $(<15 \%)$ \\
\hline \multirow[t]{2}{*}{ Elimination of absorbed dose } & $80 \%$ renal & $33 \%$ unchanged via the kidney & $27 \%$ renal & $50 \%$ renal \\
\hline & $\begin{array}{l}20 \% \text { bile (glucuronide } \\
\text { conjugation) }\end{array}$ & $\begin{array}{l}66 \% \text { metabolized in the liver into } \\
\text { inactive metabolites then eliminated } \\
\text { via the kidney or the colon in an } \\
\text { approximate } 50 \% \text { ratio }\end{array}$ & $\begin{array}{l}73 \% \text { through the liver, } \\
\text { the residue is excreted } \\
\text { by the hepatobiliary route }\end{array}$ & $\begin{array}{l}50 \% \text { metabolism and } \\
\text { biliary/intestinal excretion }\end{array}$ \\
\hline CYP substrate & No & CYP3A4, CYP2J2 & CYP3A4 & CYP3A4 (<5\%) \\
\hline P-gp substrate & DE: Yes & Yes & Yes & Yes \\
\hline BRCP substrate & No & Yes & Yes & No \\
\hline
\end{tabular}

Tmax: time to reach peak concentration; CYP3A4: cytochrome P450 isozyme 3A4;

P-gp: P-glycoprotein; BRCP: Breast cancer resistance protein 
Table 2 Items of the perioperative checklist

\begin{tabular}{|c|}
\hline THE PERIOPERATIVE CHECKLIST \\
\hline$\triangleright$ The thrombo-embolic risk of the patient \\
\hline$\triangleright$ The bleeding risk of the patient \\
\hline $\begin{array}{l}\triangleright \text { Timing of stopping DOAC before an invasive procedure: } \\
\text { - The bleeding risk of the invasive procedure } \\
\text { • The elimination half-life of the DOAC used depending } \\
\text { on the patient's } \\
\text { orenal function, liver function, and co-medication }\end{array}$ \\
\hline $\begin{array}{l}>\text { Specific considerations for some invasive procedures: } \\
{ }^{\circ} \text { Neuraxial anesthesia } \\
{ }^{\circ} \text { Atrial fibrillation ablation }\end{array}$ \\
\hline$\triangleright$ When should bridging therapy with heparin be suggested? \\
\hline$\triangleright$ Resuming a DOAC after an invasive procedure or surgery \\
\hline
\end{tabular}

Apart from these scores, patients with a recent history of stroke or transient ischemic attack (within 3 months) are considered as high TE risk. The 9th edition of the American College of Chest Physicians (ACCP) guidelines on perioperative management of antithrombotic therapy go further and suggest considering at high TE risk:

- Patients with AF and a prior stroke or transient ischemic attack (occurring $>3$ months before the planned surgery).

- Patients with a CHADS2 score $<5$ having prior thromboembolism during temporary interruption of oral anticoagulants $[32,33]$.

\section{Timing of last thrombo-embolic event}

For patients with VTE, thrombosis, thrombus propagation and embolization can occur up to 12 months after diagnosis and initiation of the treatment. The ACCP guidelines consider that during interruption of anticoagulant treatment, the risk of recurrence of VTE is a high risk if the last acute VTE occurred less than 3 months ago, an intermediate risk if VTE occurred between 3 and 12 months ago, and a low risk if the last VTE occurred at least 12 months ago. The authors recommend taking individual patient factors into consideration, such as patients with remote ( $>12$ months ago), but severe VTE associated with pulmonary hypertension. These patients may be perceived as high risk though they would be classified as low risk [32].

Regarding patients with a VTE event $<3$ months, procedures requiring DOAC discontinuation during this time interval must be discussed with a multidisciplinary team to assess the urgency of the procedure. The procedure should be postponed if possible, and if not, a bridging therapy with heparin should be discussed due to the high case fatality of recurrent VTE during the initial 3 months (11.3\% (CI, $8.0 \%$ to $15.2 \%)$ ) [35]. Caution is advised in patients with initial symptomatic pulmonary embolism (PE) as they have a higher risk of recurrent VTE than those with initial deep vein thrombosis (DVT) without PE, and as they are at higher risk of recurrent symptomatic PE [36], with a case-fatality of $26.4 \%$ (95\% CI, 16.7\%-38.1\%) [37].

\section{Other risk factors}

Patients with active cancer receiving chronic anticoagulation are prone to thrombosis and bleeding complications. Tafur et al. showed that patients with active cancer in whom anticoagulation (warfarin) was temporarily interrupted for an invasive procedure had significantly higher 3-month rates of VTE, major bleeds and death. These outcomes were observed only for those cancer patients receiving anticoagulant therapy for prior VTE events, not for patients on long-term anticoagulation for AF or mechanical heart valves (MHV) where the cancer status did not affect either thromboembolic or major bleeding outcomes [38].

Kaatz et al. showed that the 30-day postoperative incidence of stroke supports the premise that the perioperative milieu is prothrombotic [39]. Prolonged bed rest in healthy volunteers does not induce a hypercoagulability state [40], however this is not generalizable to the perioperative context and caution should be advised if prolonged immobilization is required post-surgery.

The ACCP guidelines consider certain types of surgery to be associated with an increased risk for stroke or other thromboembolism (eg, cardiac valve replacement, carotid endarterectomy, and major vascular surgery) [32].

\section{The bleeding risk of the patient}

The use of specific scores can help to assess the risk of major bleeding in patients with oral anticoagulant treatment. As these scores have never been validated in the perioperative setting to guide anticoagulant management, there is a real need to develop a bleeding risk score dedicated to surgical patients.

Different scores have been evaluated such as the HAS-BLED score [41], the ORBIT bleeding risk score [42] and the novel biomarker-based ABC- bleeding risk score. The last score performed better in predicting major bleeding in patients with atrial fibrillation than the HAS-BLED and ORBIT scores, but is probably more difficult to use in practice [43].

A high bleeding risk score should generally not suggest that oral anticoagulants are stopped, but modifiable bleeding risk factors should be identified and treated [44].

\section{Time of stopping DOACs before an invasive procedure}

Two main characteristics influence the timing for the last DOAC administration before an invasive procedure: the bleeding risk of the procedure and the elimination half-life of the DOAC. 


\section{The bleeding risk of invasive procedures}

Invasive procedures should be classified as low or high bleeding risk. Various classifications of procedural bleeding risks have been published [19, 33, 45, 46].

Each institution should have a detailed list of the bleeding risks of all the invasive procedures that are performed there such as that presented in Table 3.

There is sufficient evidence that some procedures may be performed on patients receiving anticoagulant therapy (i.e. procedures with minimal risk), as for example superficial skin surgeries, parietal surgery, cataract surgery, and minor dental procedures [47]. It is suggested that the morning dose of anticoagulant should be omitted on the day of the procedure to avoid peak concentrations during the procedures [19].

Pacemaker or cardioverter-defibrillator devices can be implanted safely without stopping VKAs, but more evidence is needed about DOACs $[48,49]$. The BRUISE CONTROL-2 trial, which is currently recruiting, aims to show that performing device surgery without interruption of the DOAC will result in a reduced rate of clinically significant hematoma [48].

\section{The elimination half-life of the DOAC}

The elimination half-life of DOACs can be increased by decreased renal function (dabigatran $>>$ edoxaban $>$ rivaroxaban and apixaban), severe liver insufficiency (rivaroxaban and apixaban $>$ edoxaban $>$ dabigatran) and co-medications.

\section{a. Renal function}

The creatinine clearance $(\mathrm{CrCl})$ must be calculated by the Cockcroft - Gault equation, as the Modified Diet in Renal Disease (MDRD) equation overestimates renal function at lower levels. Renal function should be systematically checked when underlying conditions might affect it [17].

\section{b. Liver function}

None of the perioperative proposals recommend altering DOAC pre-procedural administration in cases of liver insufficiency. However, moderate to severe, chronic liver disease can increase rivaroxaban plasma concentrations. Therefore, liver function should be regularly rechecked in chronic or acute liver impairment.

\section{c. Other risk factors}

Older age, extreme low body weight $(<50 \mathrm{~kg})$ and comedication with important drug-drug interaction should also be researched as they can increase the half-life of DOACs or anticoagulant concentrations.

Drugs that strongly inhibit CYP3A4 and P-glycoprotein (P-gp) increase bleeding risks due to increased anticoagulation concentrations [50-52]. Anti-platelet agents, antiinflammatory drugs, selective or non-selective serotonin reuptake inhibitors and all anticoagulants are medications that, while not directly affecting DOAC metabolism or transport, increase the bleeding risk when co-administrated with DOACs. Despite drug-drug interactions that frequently occur in patients treated with NVAF [53], only a few perioperative proposals recommend an extra delay before surgery in such cases [18].

Table 4 summarizes recent guidance from various expert groups.

\section{Specific consideration for some invasive procedures Neuraxial anesthesia}

Two multicenter studies have published findings on residual perioperative DOAC concentrations. Both concluded that $48 \mathrm{~h}$ without treatment might not guarantee the absence of residual anticoagulant effect at the time of the

Table 3 Examples of bleeding risk stratification for invasive procedures

\begin{tabular}{|c|c|c|}
\hline $\begin{array}{l}\text { Minimal risk of bleeding or feasible with } \\
\text { on-therapy levels of direct oral anticoagulants }\end{array}$ & Low to moderate risk of bleeding & High risk of bleeding \\
\hline $\begin{array}{l}\text { Tooth extraction: } 1 \text { to } 3 \text { teeth } \\
\text { Periodontology } \\
\text { Simple endoscopy without biopsy } \\
\text { Superficial surgery (e.g. abscess incision } \\
\text { or minor dermatologic procedures } \\
\text { (small superficial excision) } \\
\text { Cataract procedure } \\
\text { Double J stent insertion }\end{array}$ & $\begin{array}{l}\text { Endoscopy with simple biopsy } \\
\text { Prostate or bladder biopsy } \\
\text { Coronary angiography } \\
\text { Simple abdominal hernia repair } \\
\text { Anal surgery } \\
\text { Gynecologic surgery: simple total } \\
\text { laparoscopic hysterectomy } \\
\text { Orthopedic surgery: hand surgery, arthroscopy } \\
\text { Pace-maker or cardioverter-defibrillator implantation }\end{array}$ & $\begin{array}{l}\text { Neuraxial anesthesia } \\
\text { Intracranial surgery } \\
\text { Thoracic surgery } \\
\text { Cardiac surgery } \\
\text { Complex abdominal or gynecological } \\
\text { cancer surgery } \\
\text { Major orthopedic surgery } \\
\text { Ear/Nose/Throat complex cancer surgery } \\
\text { or specific surgery requiring good } \\
\text { hemostasis (e.g. cochlear implant or } \\
\text { thyroid surgery) } \\
\text { Liver and kidney biopsy } \\
\text { Transurethral prostate or bladder resection } \\
\text { Extracorporeal shockwave lithotripsy } \\
\text { Infected pace maker lead extraction } \\
\text { (increased risk of cardiac tamponade) } \\
\text { Robotic surgery }\end{array}$ \\
\hline
\end{tabular}

${ }^{a}$ We suggest realizing these procedures at trough levels of direct oral anticoagulants (e.g. avoiding the intake the morning of the procedure)

${ }^{\mathrm{b}}$ Awaiting results of BRUISECONTROL-2 trial (NCT01675076) to decide whether device procedures can be safely realized on direct oral anticoagulants 


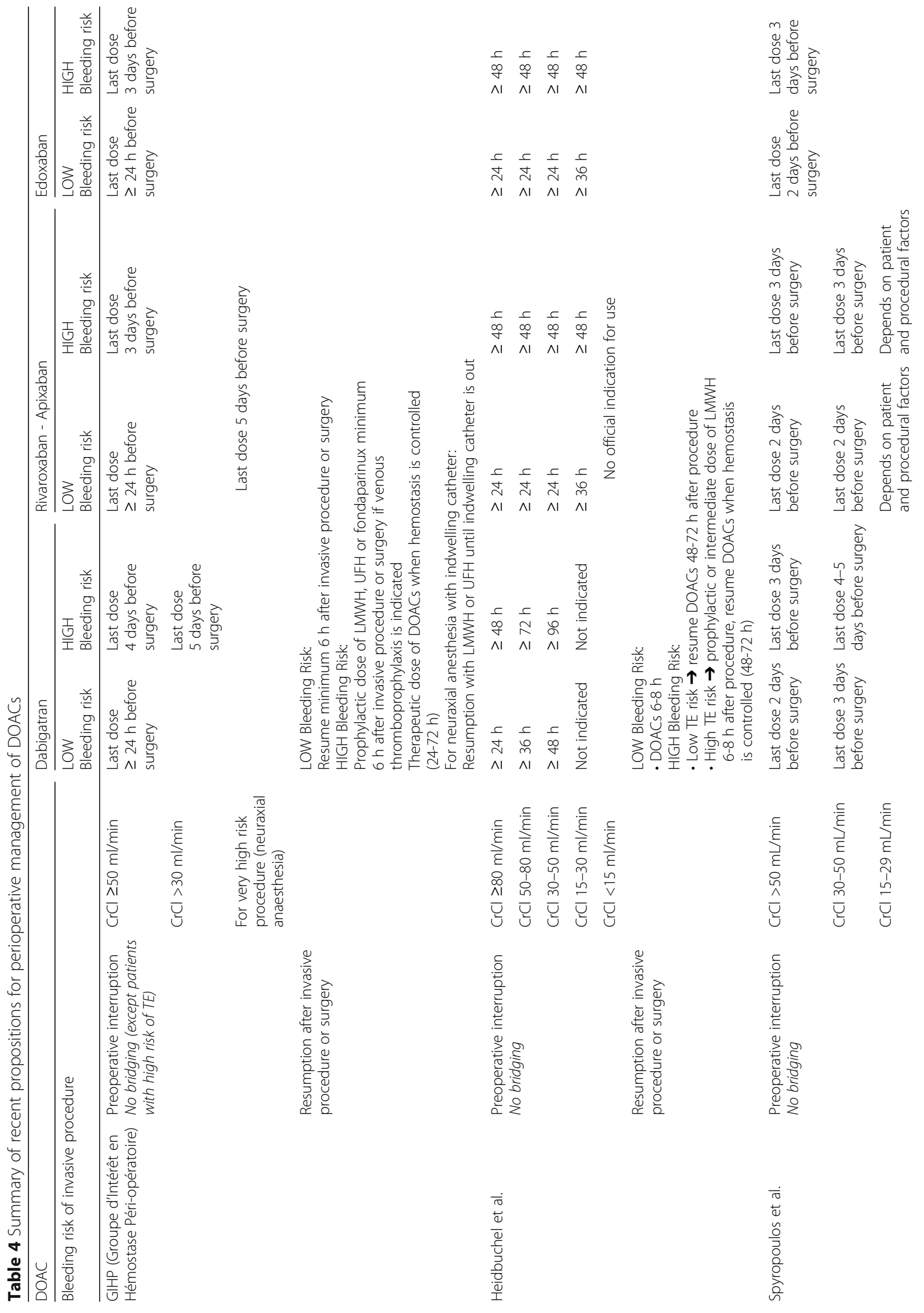


Dubois et al. Thrombosis Journal (2017) 15:14

Page 6 of 17

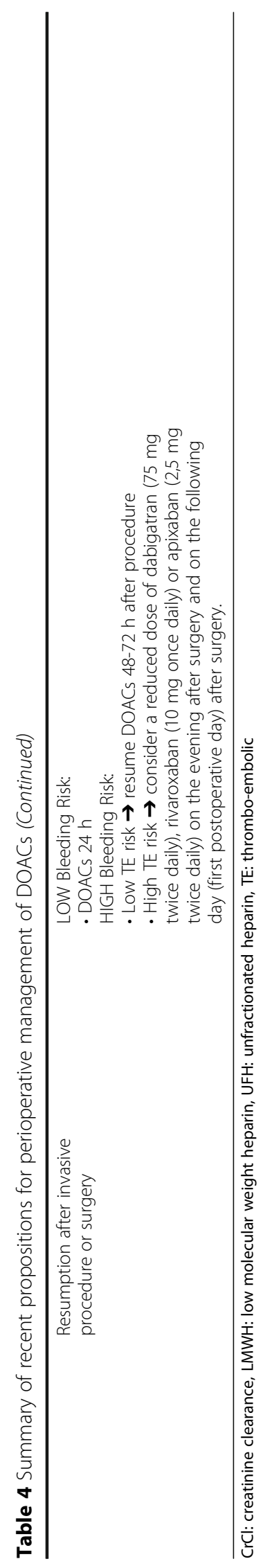


procedure in around 15\% of patients and suggested that the period of stopping a DOAC before very high bleeding risk procedures requiring complete hemostatic function such as neuraxial anesthesia or intracranial surgery should be prolonged [16, 54].

Such findings are important as some expert groups have classified these procedures as having a similar risk of bleeding as other conventional high-risk procedures and recommend a minimum $48 \mathrm{~h}$ of stopping DOAC treatment in patients with normal $\mathrm{CrCl}(>80 \mathrm{ml} / \mathrm{min})$ for dabigatran and with moderate to normal $\mathrm{CrCl}(\mathrm{CrCl}$ $>30 \mathrm{ml} / \mathrm{min}$ ) in patients on rivaroxaban, apixaban or edoxaban [45].

Yet, procedures such as neuraxial anesthesia must be considered as major bleeding risk interventions that require complete hemostatic function. The overall incidences of neuraxial hematoma in patients receiving an epidural or spinal anesthesia are estimated to be $1 /$ 220,000 and $1 / 320,000$ patients, respectively [55]. In the presence of risk factors such as multiple attempts, spinal abnormalities, inherited or acquired coagulopathies, and heparin administration, the bleeding risk can be increased by up to two orders of magnitude (e.g. 1/3600 in the study published by Moen et al. including female patients undergoing knee arthroplasty) [55-58].

Rosencher et al. [59] and Gogarten et al. [60] advise an interruption of two half-lives before neuraxial anesthesia, but firstly this recommendation is based only on the prophylactic dosage and secondly it does not take into account the huge inter and intra-individual variability of DOAC plasma concentrations [61].

Recent guidelines published by the American Society of Regional Anesthesia (ASRA) [62] recommend an interval of 5 half-lives to allow complete elimination between stopping oral anticoagulants and carrying out medium or high-risk pain procedures [62]. Due to the variability in DOAC metabolism and elimination, this interval corresponds to 4-5 days for dabigatran, and 3 days for rivaroxaban and apixaban [57, 63]. Similarly in a very cautious approach, the GIHP proposed 5 days of DOAC interruption before neuraxial anesthesia [19].

Douketis et al. commented recently on the latest ASRA guidance. With the high inter-individual variability of DOAC plasma concentration $[15,61]$, they warned that estimating the elimination half-life of DOACs using the glomerular filtration rate is not sufficient to determine the required stoppage period before neuraxial anesthesia. They suggested that the ideal timing of stopping DOAC treatment should be based on residual plasma concentration measured in the perioperative setting. Benzon et al. replied that further research projects implementing DOAC perioperative measurements need to be conducted to provide sufficient high quality evidence to guide perioperative DOAC interruption. For perioperative research purposes, the use of adapted specific laboratory tests to estimate low plasma concentration of DOACs need to be used and will be discussed in a later chapter.

\section{Atrial fibrillation ablation}

Catheter ablation (CA) for atrial fibrillation performed by venous femoral puncture is a common procedure performed worldwide. However, this procedure can cause potentially life threatening bleeding complications such as cardiac tamponade, and also carries a specific TE risk. For periprocedural anticoagulation, undergoing CA with uninterrupted warfarin became a standard as it was associated with fewer periprocedural strokes and minor bleeding complications than low molecular weight heparin (LMWH) [64]. For uninterrupted DOACs (rivaroxaban, dabigatran and apixaban), research evidence tends to the same conclusions as with uninterrupted warfarin [65-69]. However, there is an important variability in the definition of uninterrupted DOACs in the literature. For example, uninterrupted dabigatran can be defined as a last dose on the evening before CA [66] or in the morning of the procedure [70]. Studies should use a standard protocol for uninterrupted DOACs to allow comparison between results.

Unfractionated heparin (UFH) is given during the procedure for left-sided ablation as a prophylactic measure to prevent clot formation. Activated clotting time (ACT) is used to measure UFH anticoagulation during the procedure. However, several ex-vivo and in-vitro studies have shown that ACT can be influenced by concomitant DOAC in the plasma. Indeed, some studies report that it takes more time [70] and higher doses of UFH to reach the target ACT (300-400 s) than in patients undergoing $\mathrm{CA}$ with uninterrupted warfarin or acenocoumarol [70-72]. Other studies report that DOACs influence ACT baseline, according to the variable sensitivity of ACT to each DOAC and to the specific instrument used to measure ACT [73]. Further studies are needed to validate the safety and the relevance of the target ACT (300-400 s) with UFH during the procedure with uninterrupted DOACs.

\section{When should bridging therapy with heparin be suggested?}

The administration of LMWH after stopping oral anticoagulants was initially recommended to avoid a perioperative gap with insufficient anticoagulation.

The recommendations of the European Society of Anaesthesiology (ESA) published in 2013 [74] suggested that bridging therapy with heparins could be used when DOAC had a long preoperative interruption ( 5 days before surgery) in patients at high TE risk (for dabigatran, it considered patients with normal to mildly impaired 
renal function only) (grade 2C). Their categorization of patients at high risk of TE differed from the one proposed in the ACCP guidelines, as the ESA included patients with AF and CHADS2 score $>2$.

Since the latter recommendations, several studies have failed to support the benefit of heparin bridging in reducing perioperative TE at DOAC arrest.

Schulman et al. published the first prospective trial of dabigatran perioperative management, without heparin bridging, except in postoperative situations where patients were fasting or when an indwelling neuraxial catheter was in place. They included 541 patients in two years and recorded only one transient ischemic attack $(0.2 \%$; $95 \% \mathrm{CI}, 0-0.5)$. They concluded that bridging was not necessary for a standardized arrest of dabigatran in a perioperative context. However, the majority of invasive procedures had a low bleeding risk and most patients undergoing high bleeding risk procedures had a dabigatran interruption of only $48 \mathrm{~h}$, which seems insufficient for procedures like neuraxial anesthesia [21, 75-78].

Several observational studies from clinical trials or national registries have shown a higher bleeding risk without reduction of TE with the use of heparin bridging in patients taking DOACs or warfarin [79]. However, in most studies heparin bridging and anticoagulant arrest were not standardized. Furthermore, the invasive procedures had mainly low to moderate bleeding risks and patients at high TE risks were again underrepresented in these trials. Therefore the ongoing PAUSE trial (NCT02228798) which aims to recruit 3300 patients on DOACs in a perioperative setting following a standardized protocol without heparin bridging and with residual DOAC concentration measurements on the day of the invasive procedure, may be able to recruit sufficient high-TE risk patients to strengthen the conclusions of the previous trials. The estimated study completion date is December 2018.

DOACs have a shorter elimination half-life than most VKAs and therefore heparin bridging has no clinical benefit in patients with a short period of perioperative DOAC interruption. The situation might be different for patients with high TE risk and prolonged DOAC arrest (> 72-96 h), e.g. before a neuraxial anesthesia. For prolonged arrest of DOAC, when the risk of TE outweighs the risk of bleeding, patients should benefit from a multidisciplinary management to decide if heparin bridging should be prescribed in order to reduce the perioperative gap without anticoagulant. The use of heparin bridging (LMWH or UFH) requires a clear protocol that should be readily available in each institution. For example, the dose and regimen of LMWH must be adapted according to the patient's clinical characteristics (e.g. weight and renal function) including the risk of bleeding [80]. Furthermore, both are parenteral anticoagulants which may cause heparin-induced thrombocytopenia and osteoporosis. The use of UFH requires hospitalization to monitor the anticoagulant level, but it has the advantage of being eliminated independently of the patient's renal function [81]. Indeed, a recent survey demonstrated that despite the evidence that bridging with heparin should be greatly reduced in clinical practice and reserved for particularly high TE settings, many physicians involved in perioperative management still continue to bridge patients with heparin at DOAC arrest without a standardized protocol [19, 33, 45, 46].

Resuming a DOAC after an invasive procedure or surgery Advice about DOAC resumption after high bleeding-risk procedures is similar in the different expert guidelines: all recommend that therapeutic doses of DOACs should be deferred for 24-72 $\mathrm{h}[19,45,46]$. If necessary, the use of a stepwise approach of bridging therapy with a prophylactic dose of heparin can be considered for patients at high TE risks [33]. Spyropoulos et al. instead propose a reduced dose of dabigatran (75 mg twice daily), rivaroxaban (10 mg once daily) or apixaban ( $2.5 \mathrm{mg}$ twice daily) on the evening after surgery and on the day after surgery (first postoperative day). They recommend bridging therapy with heparins only in patients who cannot tolerate oral medications [19]. If patients are at high TE risks and hemostasis is not achieved, mechanical VTE prophylaxis should be considered. The GIHP suggest a bridge with heparin by the time an indwelling catheter is in place after neuraxial anesthesia [59].

For prophylactic DOAC resumption in a postoperative context, Rosencher et al. suggest that after neuraxial catheter withdrawal, the anticoagulant can be administered at "8 hours minus its time to peak concentration (Tmax)" (which varies from 1 to $4 \mathrm{~h}$ in DOACs). They suggest that it takes about $8 \mathrm{~h}$ for an initial platelet plug to solidify into a stable clot which will remain intact after administration of anticoagulants [59]. The presence of bleeding during needle puncture or catheter placement should further delay anticoagulant therapy post surgery for $24 \mathrm{~h}$ [62].

For pain procedures, the recent ASRA guidelines suggest that the first dose of DOAC can be administrated after an interval of $24 \mathrm{~h}$, unless there is a high risk of VTE. A 12-h interval can be considered in some circumstances, depending on the physician's judgement [82].

For low bleeding-risk surgery, some experts recommend restarting DOACs $6-8 \mathrm{~h}$ after the end of surgery. Spyropoulos et al. recommend waiting $24 \mathrm{~h}$ before resuming the full dose of DOAC.

Table 4 describes the main propositions about DOAC resumption in the peri-procedural setting.

Planning safe resumption of DOAC treatment is essential as premature re-initiation of heparin therapy (within $24 \mathrm{~h}$ of a procedure) is an avoidable independent predictor of major bleeding $[83,84]$. 


\section{Doac laboratory testing}

DOACs were initially marketed with the advantage of not requiring routine laboratory testing. However, use in frail or obese patients [22], as well as the management of emergencies in patients on DOACs necessitated the development of specific coagulation assays able to answer specific clinical questions accurately.

In the perioperative setting, the 2 main needs are: 1 ) to exclude clinically relevant concentrations of DOACs before a procedure carrying a high risk of bleeding (e.g. when DOAC interruption has been wrongly assessed or when emergencies require thrombolysis) and 2) to exclude supra-therapeutic plasma concentrations before urgent interventions. In addition, specific plasma levels have been suggested to warrant the administration of DOAC antidotes (i.e. $50 \mathrm{ng} / \mathrm{ml}$ for a patient with serious bleeding and $30 \mathrm{ng} / \mathrm{ml}$ in patients requiring urgent surgery that cannot be delayed and carries a high risk of bleeding) [85].

Reagents used for routine global assays such as activated partial thromboplastin time (aPTT) for dabigatran and prothrombin time (PT) for direct anti-Xa anticoagulants (rivaroxaban $>$ edoxaban $>>$ apixaban) are not sufficiently accurate to exclude clinically relevant plasma concentrations of DOACs [86-88]. However, both global assays can provide a qualitative assessment of DOACs in the on-therapy range, but their performances depend strongly on the reagent used and for apixaban, even high therapeutic levels may not be detected with PT $[89,90]$. In contrast, the thrombin time is very sensitive to the presence of dabigatran and a normal TT excludes this [90]. However, slightly elevated TT does not assess accurately the residual effect of dabigatran due to lack of standardization. Furthermore, the sensitivity of various thrombin reagents can give different TT measurements for the same dabigatran plasma concentration [91-95].

Routine tests are not specific to DOAC and can be prolonged in many situations (e.g. trauma-induced coagulopathy) outside the intake of DOACs. This may lead to incorrect estimation of DOAC anticoagulant level.

For accurate estimation of DOAC plasma concentrations, laboratories must use specific assays with the appropriate methods for the expected DOAC plasma level. The choice of method will depend on the question the clinician needs to answer.

Some specific coagulation assays have adapted calibrators and methods for low plasma DOAC concentrations and these should therefore be used to assess levels $<50 \mathrm{ng} / \mathrm{ml}$ [95]. These tests can provide accurate estimation in the perioperative setting when clinically relevant DOAC concentrations need to be excluded or when the estimation of DOAC plasma concentrations will guide antidote administration [23].
Importantly, laboratory scientists and clinicians should collaborate to establish an institutional protocol on when and how to test patients on DOACs to highlight what information is needed, to propose the appropriate tests and to provide the correct interpretation of results.

In addition, laboratories need to be informed about any clinical aspects of the patient that might influence the results (e.g. heparin bridging) so they can use the most appropriate test available or to adapt estimates of DOAC plasma concentrations and their significance.

Recently, experts highlighted the urgent need to make accurate, specific coagulation assays widely available [96] and the need for further research to improve the turn-around time of such tests (ideally less than $20 \mathrm{~min}$ ) to speed up emergency management of patients on DOACs.

\section{Other options to rapidly screen for the presence of DOACs}

When a patient is unconscious and the clinical history is not available, the presence of dabigatran can be excluded if the TT is normal or its presence suspected if the TT is elevated. However, there is no routine assay with similar sensitivity for anti-Xa DOACs (rivaroxaban, apixaban and edoxaban), and therefore some authors reported the use of UFH or LMWH-calibrated heparin assays to screen the presence (or absence) of significant levels of a FXa DOAC. Indeed, LMWH- or UFH-calibrated methods can exclude significant levels of anti-Xa DOACs $(<30 \mathrm{ng} / \mathrm{ml})$ and most coagulation analyzers can run the heparin assays. Furthermore, FDA-approved heparin calibrators and controls are commercially available, which is not the case for anti-Xa DOACs [97-100].

Although heparin assays are not specific and cannot distinguish between heparins and anti-Xa DOACs, their use could assist clinicians in emergency situations where the clinical history is not available (i.e. excluding anti-Xa activity in an unconscious patient who may benefit from thrombolysis).

One promising global assay that could be implemented easily on all coagulometers is the dilute Russell's Viper Venom Time (dRVV-T). Recent data suggest that this test could provide a rapid estimation of the intensity of anticoagulation with all DOACs without any specific calibrators, and the test can identify sub-therapeutic plasma levels. However, further studies are needed to confirm its clinical utility, as it is currently less widely available than the TT or the anti-Xa chromogenic assays [101].

\section{Point of care monitoring and other global assays}

Point-of-care (POC) monitoring and other global assays (e.g. thrombin generation assay (TGA), prothrombinase induced clotting time (PiCT), thromboelastography (TEG), thromboelastometry (TEM), and activated clotting time 
(ACT)) have been tested for various DOACs. They can be useful to assess the efficacy of reversal agents. However, they are costly, lack standardization, are insufficiently studied and are not available in routine clinical practice $[22,23,102]$. In addition, they are often not sensitive enough to exclude clinically relevant concentrations of DOACs in the perioperative setting. Their use should therefore be restricted to specific clinical contexts.

\section{Management of emergencies}

Most episodes of bleeding in patients treated with DOACs can be managed with supportive measures and natural clearance of the drug.

A rapid assessment of the patient's anticoagulation level helps to determine the contribution of the anticoagulant to the bleeding, the need for a reversal strategy and to plan the best timing if an invasive procedure is required [102].

If emergencies require an invasive procedure that can be postponed, the timing for the procedure should be determined from the bleeding risk of the procedure and the residual anticoagulant level of DOACs. The GIHP suggest that a residual DOAC plasma concentration $<30 \mathrm{ng} / \mathrm{ml}$ should be reached before undertaking high bleeding risk surgery [102, 103]. A level $>400 \mathrm{ng} / \mathrm{ml}$ suggests a high risk of uncontrollable hemorrhage [22].

Recent ISTH guidance for the administration of DOAC antidotes [104] is partly based on DOAC plasma concentration. Experts consider that a threshold $\geq 50 \mathrm{ng} /$ $\mathrm{ml}$ warrants the administration of an antidote in cases of serious bleeding. For urgent invasive procedures carrying a high risk of bleeding, the threshold is $\geq 30 \mathrm{ng} / \mathrm{ml}$. If specific coagulation assays with calibrators accurate for low DOAC plasma concentrations are not available to guide antidote administration, a normal TT and the absence of anti-Xa activity measured with LMWH- or UFH-calibrated methods can rapidly avoid unnecessary antidote administration.

Patients who have bled may have an acquired coagulopathy (e.g. polytrauma-induced coagulopathy or dilutional coagulopathy) in addition to anticoagulant therapy. Early administration of hemostatic therapy such as prothrombin complex concentrates (PCCs), fibrinogen concentrates, fresh frozen plasma, platelets and antifibrolytics may be critical for preventing complex coagulopathies and progression to severe, life-threatening hemorrhage [105].

In the absence of an antidote, previously suggested reversal strategies can be considered:

- reduction of intestinal absorption: activated charcoal should be considered in the first hours after ingestion [106].
- increase in DOAC clearance: ensure adequate diuresis, especially for patients taking dabigatran. Only patients on supratherapeutic level of dabigatran may be candidates for renal replacement therapy (RRT) when an invasive procedure needs to be rapidly planned. However, within $4 \mathrm{~h}$ after RRT, a rebound of dabigatran plasma concentration can occur with a potential risk of bleeding [104].

- administration of coagulation factors: Prothrombin complex concentrates (PCCs) contain lyophilized human plasma-derived vitamin- $\mathrm{K}$ dependent coagulation factors (clotting factors II, VII, IX and $\mathrm{X}$ ) and are standardised according to their factor IX content. They may also contain anticoagulation proteins such as protein $\mathrm{C}$, protein $\mathrm{S}$, protein $\mathrm{Z}$, antithrombin and heparin. They are categorized as 4-factor PCC if their content of FVII is high and as 3-factor PCC if it is low. Furthermore, aPCCs $\left(\mathrm{FEIBA}^{\circ}\right)$ are available which contain non-activated factors II, IX and X, and activated factor VII [104]. Prophylactic administration of PCCs is not recommended. The mechanisms of action of PCCs and aPCCs are similar as both increase thrombin generation and animal studies have not shown any significant differences in the reduction of bleeding. Therefore, it is not useful to switch from one to the other when trying to manage bleeding in a patient on dabigatran $[45,103]$. In the pre-clinical setting, PCC or aPCC showed an improvement in coagulation parameters, blood loss and mortality. Dose recommendations are difficult to make with the lack of high-level evidence with PCCs and aPCCs for dabigatran reversal, but it appears necessary to use the minimum effective dose because of the theoretical thromboembolic risk (starting with an initial dose of $25 \mathrm{U} / \mathrm{kg}$ ). Suggested doses for 4-Factor PCCs and aPCC are $50 \mathrm{U} / \mathrm{kg}$ and $80 \mathrm{U} / \mathrm{kg}$ respectively.

In a recent prospective cohort study of dabigatranassociated major bleeding, the effectiveness of activated prothrombin complex concentrate (median first dose: 44 units/kg, range: 24-98), was assessed as good in 9/14 patients and moderate in 5/14 patients. No thromboembolic events occurred within 30 days [107].

Concerning recombinant factor VIIa (rVIIa), as it did not provide any advantages over PCC or aPCC, recent guidance has withdrawn rVIIa from potential reversal treatment for DOAC in bleeding patients [22].

\section{Antidotes}

The ISTH guidance state that potential indications for antidotes include life-threatening bleeding, bleeding into a critical organ or closed space, prolonged bleeding despite local hemostatic measures, high risk of recurrent 
bleeding because of overdose or delayed clearance of DOACs, and need for an urgent intervention associated with a high risk of bleeding. Antidotes should not be used when bleeding can be stopped with local hemostatic measures or when interventions can be delayed to enable anticoagulant clearance, especially in patients with normal renal function [108]. Some urgent procedures without bleeding may have antidote administration delayed into the operating room, e.g. for patients with clinically relevant DOAC plasma concentration and unsatisfactory hemostatic conditions.

\section{Antidote for dabigatran etexilate}

Idarucizumab is a specific reversal agent for dabigatran [108]. It is a humanized mouse monoclonal antibody fragment (Fab) that specifically binds to dabigatran with high affinity (approximately 350-fold greater than the affinity of dabigatran for thrombin) and neutralizes its anticoagulant effect. Idarucizumab, when attached to dabigatran, prevents the latter binding to thrombin. It has an estimated half-life of $45 \mathrm{~min}$ [109].

According to the clinical study REVERSE AD Phase III, idarucizumab should be given at a dose of $5 \mathrm{~g}$ once via a 5-min intravenous infusion. At this dosage of idarucizumab, the reversibility period of the anticoagulant effect of dabigatran is complete, immediate and sustained $[109,110]$.

No specific side effects have been attributed to idarucizumab yet, and no changes in coagulation markers in blood tests in the absence of dabigatran [111].

After publication of the first results of the REVERSE AD phase III trial, idarucizumab received an accelerated marketing approval from the FDA and EMA and is now licensed in the United States and European countries for the reversal of the anticoagulant effect of dabigatran in life-threatening or uncontrolled bleeding and urgent surgery or invasive procedures $[112,113]$.

Some limitations of the REVERSE AD trial should be considered. First, the primary end point was not patients' clinical outcomes, but normalization of laboratory tests to demonstrate the maximum percentage reversal of the anticoagulant effect of dabigatran (measured with the dilute thrombin time or ecarin clotting time). Two groups of patients on dabigatran were included, 298 patients in group A who had serious bleeding, and 196 patients in group B who required an urgent procedure. The dTT normalized within $4 \mathrm{~h}$ in $235 / 238$ patients (98.7\%) in group A and 141/143 patients (98.6\%) in group B. Clinical outcomes, considered only as secondary endpoints, were assessed by the treating clinician. It is important to note that the median time to the cessation of bleeding in group A was $3.5 \mathrm{~h}$ for GI bleeds and $4.5 \mathrm{~h}$ for non GI and non ICH bleeds after idarucizumab administration. The authors admitted that this endpoint was difficult to assess in many patients, such as those with intracranial or retroperitoneal bleeding.

Secondly, 51 of the 494 patients who received idarucizumab did not have prolonged dTT in the emergency department, due to dabigatran clearance. Thrombotic events occurred in 31 of 496 patients at 90 days (6.3\%). Two thirds received no antithrombotic therapy prior to the event (i.e. VTE, myocardial infarct, ischemic stroke, systemic embolism).

The worrying death rate (18.7\% in group A and 18.5\% in group B) was, according to the authors, related to the index event or associated with coexisting conditions.

Third, in some patients, there were subsequent increases in dabigatran concentrations $12 \mathrm{~h}$ and $24 \mathrm{~h}$ after idarucizumab administration. This was probably due to redistribution of extravascular dabigatran into the intravascular compartment, In addition, 7 patients received more than 1 dose of $5 \mathrm{~g}$ idarucizumab.

Finally, a major limitation is the lack of a control group with current guidance recommending prothrombin complex concentrates for the management of serious bleeding in dabigatran-treated patients [114].

As this study was not designed to demonstrate a clear benefit in patient outcomes, compared with other reversal strategies, clinicians need to be aware of these limitations and should provide an institutional protocol to guide the administration of idarucizumab and to enable appropriate patient follow-up.

\section{Antidote for oral factor $\mathrm{Xa}$ inhibitors}

Andexanet alpha is a recombinant modified human factor Xa decoy, which is catalytically inactive but able to bind direct factor Xa inhibitors with high affinity at its active site, as well as LMWH or fondaparinux.

Andexanet alpha causes a rapid and reproducible reversal of anticoagulant effects in healthy volunteers receiving rivaroxaban, apixaban, edoxaban or enoxaparin [115]. It has a half-life of approximately $1 \mathrm{~h}$ and the maximum effect is achieved after $2-5 \mathrm{~min}$. The dosing strategies used in the phase II clinical trials were different for rivaroxaban (clinical trial ANNEXA-R) and apixaban (clinical trial ANNEXA-A) due to different pharmacokinetic and pharmacodynamic models. An andexanet alpha bolus injection needs to be followed by a continuous intravenous infusion for $2 \mathrm{~h}$ due to a rebound effect of factor Xa inhibitors within 15 min of the bolus.

To reverse the effects of rivaroxaban at a daily dose of $20 \mathrm{mg}$, the recommended bolus of andexanet alpha is $800 \mathrm{mg}$ IV (30 mg per minute) followed by a continuous infusion of $8 \mathrm{mg} / \mathrm{min}$ for $2 \mathrm{~h}$ (960 $\mathrm{mg}$ in total). For apixaban at a dose of $5 \mathrm{mg}$ twice a day, the recommended bolus of andexanet alpha is $400 \mathrm{mg}$ IV $(30 \mathrm{mg}$ per minute) followed by a continuous infusion of $4 \mathrm{mg} /$ min for $2 \mathrm{~h}$ (480 $\mathrm{mg}$ in total). 
No serious adverse events or thrombotic complications were recorded in the ANNEXA-A and ANNEXA-R studies, which included 101 patients receiving andexanet alpha.

Recently, results from the phase III trial, the « Prospective, Open-Label Study of Andexanet Alfa in Patients Receiving a Factor Xa Inhibitor Who Have Acute Major Bleeding » (ClinicalTrials.gov number, NCT02329327) have been published. The authors evaluated 67 patients with acute major bleeding within $18 \mathrm{~h}$ of the last FXa inhibitor administration. Most bleeds were from gastrointestinal or intracranial sites. Andexanet alpha was administrated in a mean $(+-\mathrm{SD})$ time of $4.8 \mathrm{~h}+-1.8 \mathrm{~h}$ after emergency department admission. After bolus administration and the two hour infusion, the median antiFXa activity decreased by $86 \%$ from baseline among patients on rivaroxaban and by $92 \%$ among those receiving apixaban. At $12 \mathrm{~h}$ after andexanet alpha administration, the median anti-FXa activity had decreased from baseline by $64 \%$ for rivaroxaban, and $31 \%$ for apixaban. At this time, the clinical hemostasis was estimated as excellent or good in 37 of 47 patients. Rates of excellent or good efficacy occurred in $84 \%$ of cases for gastrointestinal bleeding and $80 \%$ for intracranial bleeding.

As for idarucizumab, this study also had limitations due to a lack of control group. Furthermore, the death rate was $15 \%$ and the high increase of anti-FXa activity at $4 \mathrm{~h}$ raises questions of the real contribution of andexanet alpha to the evaluation of the clinical hemostasis. Finally, $18 \%$ of patients had an ischemic event during the 30-day follow-up period after the infusion of andexanet. Only $27 \%$ of patients resumed anticoagulant therapy within 30 days after acute major bleeding. Birocchi et al. have asked recently if resuming anticoagulant therapy soon after an effective hemostasis could reduce thrombotic events. In conclusion, additional information needs to be collected about the safety of andexanet alpha.

\section{Universal antidote}

The third approach is the small molecule ciraparantag, which antagonizes the effects of all anticoagulants tested, except VKAs and argatroban. Ciraparantag consists of a small, water-soluble, cationic and synthetic molecule that binds LMWH, UFH, FIIa and FXa inhibitors by non-covalent binding. It can be perceived as a universal antidote for many potential anticoagulant molecules [116]. In vitro studies have shown no major interactions with other coagulation factors or albumin. Animal studies showed a reduction in the blood loss induced by DOACs [117]. In an in vivo study of healthy volunteers who were either untreated or pre-treated with $60 \mathrm{mg}$ of edoxaban, ciraparantag did not induce serious adverse events or a procoagulant signal (measured by D-dimer, TFPI, prothrombin fragments 1.2). A single bolus of 100 to $300 \mathrm{mg}$ of IV ciraparantag normalized the whole blood clotting time to less than $10 \%$ above baseline within $30 \mathrm{~min}$ in volunteers treated with $60 \mathrm{mg}$ of edoxaban with a stable effect lasting for $24 \mathrm{~h}$. Monitoring the reversal effect of ciraparantag will be challenging in clinical practice as blood collected with sodium citrate, oxalate, EDTA or heparin disrupts the ciraparantag anticoagulant complex and frees the anticoagulant in the plasma. Furthermore, kaolin and celite-based assays are insensitive to monitor the reversal effect of ciraparantag as these activators adsorb the antidote and reduce its active concentration in a blood sample [117].

\section{Why should we monitor the anticoagulant effect with antidote administration?}

The time since last DOAC intake and laboratory tests (including $\mathrm{CrCl}$ ) can guide clinicians in administering an antidote. The residual anticoagulant effect can only be accurately estimated with specific laboratory tests. However, even if the antidote is administered before the availability of DOAC plasma estimation, understanding the initial concentration at a later time may help to assess the efficacy of the dosage. Indeed, it is important to assess if a single administration is sufficient to decrease the anticoagulant activity to a safe level and to check for potential rebound effects in patients with initial supra-therapeutic DOAC levels or decreased DOAC clearance.

A recent case report described a patient with a plasma dabigatran concentration of $3337.3 \mathrm{ng} / \mathrm{ml}$ (assessed by HemosIL ${ }^{\oplus}$ DTI, Instrumentation Laboratory, United States) which decreased to $513.5 \mathrm{ng} / \mathrm{ml}$ a few minutes after the administration of $5 \mathrm{~g}$ idarucizumab. Seven hours later, the dabigatran level rebounded to $1126 \mathrm{ng} / \mathrm{ml}$.

DOACs distribute within the intra- and extra-vascular compartments, and rebound anticoagulant levels after antidote administration have been described, especially in patients with impaired renal function taking dabigatran. This rebound effect also applies to dabigatran after hemodialysis [118]. In patients with impaired renal function, the reversal of idarucizumab should be monitored after $24 \mathrm{~h}$ to exclude dabigatran reappearance if bleeding reoccurs later or an invasive procedure needs to be planned.

Noting the findings from the phase III trial of andexanet alpha, the increase of FXA inhibitor activity $4 \mathrm{~h}$ after the end of the infusion should be carefully monitored, especially if patients are still in the operating room for a high risk bleeding procedure, or if they start to bleed again. Interestingly, in $10 \%$ of the patients with the highest anti-Xa activity after antidote reversal (median anti-Xa activity $327 \mathrm{ng} / \mathrm{ml}$ at the end of the infusion) clinicians considered their clinical hemostasis to be excellent or good [119]. 
Specific laboratory tests are the only means to distinguish recurrent bleeding due to anti Xa factors or acquired coagulopathy.

In a recent review Greinacher et al. described the potential issues with the development of immunogenicity due to antidote use with DOACs and argue the need to monitor this [120].

Physicians should keep in mind that despite the ability of antidotes to reverse the anticoagulant effects of DOACs, their impact on survival still needs to be proved. Postmarketing registries are needed to determine their clinical utility, especially before thrombolytic therapy in patients with acute ischemic stroke or when additional dosing is necessary due to incomplete reversal and ongoing bleeding $[22,121]$.

\section{Conclusions}

The correct management of DOACs in the perioperative setting, requires a good understanding of DOAC pharmacokinetics, indications, drug-drug interactions and their effects on laboratory assays. This information should enable clinicians to easily recognize possible problems and solve them.

Decisions in elective situations about when to stop DOACs perioperatively must be based on their half-life, the bleeding risk of the invasive procedures, and on the thromboembolic risk of the patient. Due to the high inter-individual variability of DOAC plasma concentrations, laboratory testing may be useful for specific populations and clinical contexts.

Further perioperative research studies are necessary to confirm previous guidance based on pharmacological and/or laboratory approaches, especially for the management of emergencies or procedures with a high risk of bleeding. The question of whether patients with high TE risks need to be bridged with heparins during prolonged perioperative interruption of DOACs is still not answered. The administration of antidotes needs to be assessed via registries to validate their benefit in outcomes such as survival in patients undergoing emergency procedures with bleeding complications.

\section{Abbreviations}

DOACs: Direct oral anticoagulants; VKAs: Vitamin K antagonists; VTE: Venous thromboembolism; NVAF: Non-valvular atrial fibrillation; CrCl: Creatinine clearance; AF: Atrial fibrillation; TE: Thrombo-embolism; ACCP: American College of Chest Physicians; MHV: Mechanical heart valves; GDF-15: Growth differentiation factor-15; CTnT-hs: high-sensitivity cardiac troponin T; GIHP: Groupe d'Intérêt en Hémostase Péri-opératoire - Working Group on Perioperative Haemostasis; EHRA: European Heart Rhythm Association; MDRD: Modified Diet in Renal Disease; P-gp: P-glycoprotein; ASRA: American Society of Regional Anesthesia; CA: Catheter ablation; LMWH: Low Molecular Weight Heparin; UFH: Unfractionated Heparin; ACT: Activated Clotting Time; ESA: European Society of Anaesthesiology; Cl: Confidence interval; OR: Odds ratio; aPTT: Activated partial thromboplastin time; PT: Prothrombin time; TT: Thrombin time; POC: Point-of-care; TGA: Thrombin generation assay; PiCT: Prothrombinase induced clotting time; TEG: Thromboelastography: TEM: Thromboelastometry; dTT: diluted Thrombin Time; DRWT: Dilute Russell viper venom time; ISTH: International Society of Thrombosis and Haemostasis; ECT: Ecarin clotting time; TFPI: Tissue factor pathway inhibitor RRT: Renal replacement therapy; PCCs: Prothrombin complex concentrates; aPCC: Activated prothrombin complex concentrates

\section{Acknowledgements}

The authors thank Dr. Elizabeth Wager for language editing.

Funding

Not applicable.

Availability of data and materials

Not applicable.

\section{Authors' contributions}

Virginie Dubois, Anne-Sophie Dincq, Jonathan Douxfils, François Mullier and Sarah Lessire each drafted sections of this manuscript. François Mullier and Sarah Lessire coordinated the writing. All the authors reviewed and agreed the final manuscript.

\section{Competing interests}

The authors declare that they have no competing interests.

Consent for publication

Not applicable.

Ethics approval and consent to participate

Not applicable.

\section{Author details}

'Université catholique de Louvain, CHU UCL Namur, Department of Anesthesiology, Yvoir, Belgium. ${ }^{2}$ Namur Thrombosis and Hemostasis Center (NTHC), NAmur Research Institute of LIfe Sciences (NARILIS), Namur, Belgium. ${ }^{3}$ Université de Namur, Department of Pharmacy, Faculty of Medecine, Namur, Belgium. ${ }^{4}$ Université Libre de Bruxelles, Erasme University Hospital,Department of Anesthesiology, Brussels, Belgium. ${ }^{5}$ Université Paris Descartes, Cochin University Hospital,Department of Anesthesiology and Intensive Care, Paris, France. ${ }^{6}$ Université catholique de Louvain, $\mathrm{CHU}$ UCL Namur, Hematology Laboratory, Yvoir, Belgium.

Received: 27 November 2016 Accepted: 4 May 2017

Published online: 15 May 2017

References

1. Mega JL, Braunwald E, Wiviott SD, Bassand JP, Bhatt DL, Bode C, Burton P, Cohen M, Cook-Bruns N, Fox KA, et al. Rivaroxaban in patients with a recent acute coronary syndrome. N Engl J Med. 2012;366:9-19.

2. Investigators $E$, Bauersachs $R$, Berkowitz SD, Brenner B, Buller HR, Decousus $\mathrm{H}$, Gallus AS, Lensing AW, Misselwitz F, Prins MH, et al. Oral rivaroxaban for symptomatic venous thromboembolism. N Engl J Med. 2010;363:2499-510.

3. Schulman S, Kakkar AK, Goldhaber SZ, Schellong S, Eriksson H, Mismetti P, Christiansen AV, Friedman J, Le Maulf F, Peter N, et al. Treatment of acute venous thromboembolism with dabigatran or warfarin and pooled analysis. Circulation. 2014;129:764-72.

4. Granger CB, Alexander JH, McMurray JJ, Lopes RD, Hylek EM, Hanna M, Al-Khalidi HR, Ansell J, Atar D, Avezum A, et al. Apixaban versus warfarin in patients with atrial fibrillation. N Engl J Med. 2011;365:981-92.

5. Patel MR, Mahaffey KW, Garg J, Pan G, Singer DE, Hacke W, Breithardt G, Halperin JL, Hankey GJ, Piccini JP, et al. Rivaroxaban versus warfarin in nonvalvular atrial fibrillation. N Engl J Med. 2011;365:883-91.

6. Connolly SJ, Ezekowitz MD, Yusuf S, Eikelboom J, Oldgren J, Parekh A, Pogue J, Reilly PA, Themeles E, Varrone J, et al. Dabigatran versus warfarin in patients with atrial fibrillation. N Engl J Med. 2009;361:1139-51.

7. Lassen MR, Gallus A, Raskob GE, Pineo G, Chen D, Ramirez LM. Investigators A-: Apixaban versus enoxaparin for thromboprophylaxis after hip replacement. N Engl J Med. 2010;363:2487-98.

8. Lassen MR, Raskob GE, Gallus A, Pineo G, Chen D, Hornick P, investigators A. Apixaban versus enoxaparin for thromboprophylaxis after knee replacement (ADVANCE-2): a randomised double-blind trial. Lancet. 2010;375:807-15.

9. Eriksson BI, Dahl OE, Rosencher N, Kurth AA, van Dijk CN, Frostick SP, Kalebo P, Christiansen AV, Hantel S, Hettiarachchi R, et al. Oral dabigatran etexilate 
vs. subcutaneous enoxaparin for the prevention of venous thromboembolism after total knee replacement: the RE-MODEL randomized trial. J Thromb Haemost. 2007;5:2178-85.

10. Eriksson $\mathrm{Bl}$, Dahl OE, Huo MH, Kurth AA, Hantel S, Hermansson K Schnee JM, Friedman RJ, Group R-NIS. Oral dabigatran versus enoxaparin for thromboprophylaxis after primary total hip arthroplasty (RE-NOVATE $\|^{*}$ ). A randomized, double-blind, non-inferiority trial. Thromb Haemost. 2011;105:721-9.

11. Eriksson BI, Kakkar AK, Turpie AG, Gent M, Bandel TJ, Homering M, Misselwitz F, Lassen MR. Oral rivaroxaban for the prevention of symptomatic venous thromboembolism after elective hip and knee replacement. J Bone Joint Surg Br. 2009;91:636-44.

12. Sie P, Samama CM, Godier A, Rosencher N, Steib A, Llau JV, Van der Linden P, Pernod G, Lecompte T, Gouin-Thibault I, et al. Surgery and invasive procedures in patients on long-term treatment with direct oral anticoagulants: thrombin or factor-Xa inhibitors. Recommendations of the Working group on Perioperative Haemostasis and the French study group on thrombosis and Haemostasis. Arch Cardiovasc Dis. 2011;104:669-76.

13. Ferrandis R, Castillo J, de Andres J, Gomar C, Gomez-Luque A, Hidalgo F, Llau JV, Sierra P, Torres LM. The perioperative management of new direct oral anticoagulants: a question without answers. Thromb Haemost. 2013;110:515-22.

14. Dincq AS, Lessire S, Douxfils J, Dogne JM, Gourdin M, Mullier F. Management of non-vitamin $\mathrm{K}$ antagonist oral anticoagulants in the perioperative setting. Biomed Res Int. 2014;2014:385014.

15. Douketis JD, Wang G, Chan N, Eikelboom JW, Syed S, Barty R, Moffat KA, Spencer FA, Blostein M, Schulman S. Effect of standardized perioperative dabigatran interruption on the residual anticoagulation effect at the time of surgery or procedure. J Thromb Haemost. 2016;14:89-97.

16. Godier A, Martin AC, Leblanc I, Mazoyer E, Horellou MH, Ibrahim F, Flaujac C, Golmard JL, Rosencher N, Gouin-Thibault I. Peri-procedural management of dabigatran and rivaroxaban: duration of anticoagulant discontinuation and drug concentrations. Thromb Res. 2015;136:763-8.

17. Heidbuchel H, Verhamme P, Alings M, Antz M, Diener HC, Hacke W, Oldgren J, Sinnaeve P, Camm AJ, Kirchhof P. Updated European heart Rhythm Association practical guide on the use of non-vitamin $K$ antagonist anticoagulants in patients with non-valvular atrial fibrillation. Europace. 2015;17:1467-507

18. Faraoni D, Levy JH, Albaladejo P, Samama CM, Groupe d'Interet en Hemostase P. updates in the perioperative and emergency management of non-vitamin K antagonist oral anticoagulants. Crit Care. 2015;19:203.

19. Albaladejo P, Bonhomme F, Blais N, Collet JP, Faraoni D, Fontana P, Godier A, Llau J, Longrois D, Marret E, et al. Management of direct oral anticoagulants in patients undergoing elective surgeries and invasive procedures: updated guidelines from the French Working group on Perioperative Hemostasis (GIHP) - September 2015. Anaesth Crit Care Pain Med. 2017 Feb;36(1):73-6.

20. Healey JS, Eikelboom J, Douketis J, Wallentin L, Oldgren J, Yang S, Themeles $E$, Heidbuchel $H$, Avezum A, Reilly $P$, et al. Periprocedural bleeding and thromboembolic events with dabigatran compared with warfarin: results from the randomized evaluation of long-term anticoagulation therapy (RELY) randomized trial. Circulation. 2012;126:343-8.

21. Sherwood MW, Douketis JD, Patel MR, Piccini JP, Hellkamp AS, Lokhnygina Y, Spyropoulos AC, Hankey GJ, Singer DE, Nessel CC, et al. Outcomes of temporary interruption of rivaroxaban compared with warfarin in patients with nonvalvular atrial fibrillation: results from the rivaroxaban once daily, oral, direct factor Xa inhibition compared with vitamin K antagonism for prevention of stroke and embolism trial in atrial fibrillation (ROCKET AF). Circulation. 2014;129:1850-9.

22. Levy JH, Ageno W, Chan NC, Crowther M, Verhamme P, Weitz Jl. Subcommittee on control of a: when and how to use antidotes for the reversal of direct oral anticoagulants: guidance from the SSC of the ISTH. J Thromb Haemost. 2016;14:623-7.

23. Weitz JI, Eikelboom JW. Urgent need to measure effects of direct oral anticoagulants. Circulation. 2016;134:186-8.

24. Pradaxa : EPAR - Product Information - 28/01/2016 Pradaxa -EMEA/H/C/ 000829 -II/0089 [http://www.ema.europa.eu/docs/en_GB/document_library/ EPAR_-_Product_Information/human/000829/WC500041059.pdf].

25. Xarelto -EMEA/H/C/000944 -IB/0040/G - Product Information [http://www. ema.europa.eu/docs/en_GB/document_library/EPAR_-_Product_ Information/human/000944/WC500057108.pdf].
26. Eliquis -EMEA/H/C/002148 -R/0034 - Product Information [http://www.ema. europa.eu/docs/en_GB/document_library/EPAR_-_Product_Information/ human/002148/WC500107728.pdf].

27. Lixiana -EMEA/H/C/002629 -IB/0002 - Product information [http://www.ema europa.eu/docs/en_GB/document_library/EPAR_-_Product_Information/ human/002629/WC500189045.pdf].

28. Lip GY, Nieuwlaat R, Pisters R, Lane DA, Crijns HJ. Refining clinical risk stratification for predicting stroke and thromboembolism in atrial fibrillation using a novel risk factor-based approach: the euro heart survey on atrial fibrillation. Chest. 2010;137:263-72.

29. Lip GY, Andreotti F, Fauchier L, Huber K, Hylek E, Knight E, Lane D, Levi M, Marin F, Palareti G, et al. Bleeding risk assessment and management in atrial fibrillation patients. Executive summary of a position document from the European heart Rhythm Association [EHRA], endorsed by the European Society of Cardiology [ESC] Working group on thrombosis. Thromb Haemost. 2011;106:997-1011.

30. Jacobs V, May HT, Bair TL, Crandall BG, Cutler M, Day JD, Weiss JP, Osborn JS, Muhlestein JB, Anderson JL, et al. The impact of risk score (CHADS2 versus (HA2DS2-VASC) on long-term outcomes after atrial fibrillation ablation. Heart Rhythm. 2015;12:681-6.

31. Kaatz S, Douketis JD, Zhou H, Gage BF, White RH. Risk of stroke after surgery in patients with and without chronic atrial fibrillation. J Thromb Haemost. 2010;8:884-90

32. Douketis JD, Spyropoulos AC, Spencer FA, Mayr M, Jaffer AK, Eckman MH, Dunn AS, Kunz R. Perioperative management of antithrombotic therapy: antithrombotic therapy and prevention of thrombosis, 9th ed: American College of Chest physicians evidence-based clinical practice guidelines. Chest. 2012:141:e326S-50S

33. Spyropoulos AC, Al-Badri A, Sherwood MW, Douketis JD. Periprocedural Management of Patients on a vitamin $\mathrm{K}$ antagonist or a direct oral anticoagulant requiring an elective procedure or surgery. J Thromb Haemost. 2016 May; 14(5):875-85.

34. Tafur A, Douketis JD. Perioperative anticoagulant management in patients with atrial fibrillation : practical implications of recent clinical trials. Pol Arch Med Wewn. 2015;125:666-71

35. Carrier M, Le Gal G, Wells PS, Rodger MA. Systematic review: case-fatality rates of recurrent venous thromboembolism and major bleeding events among patients treated for venous thromboembolism. Ann Intern Med. 2010;152:578-89.

36. Eichinger S, Weltermann A, Minar E, Stain M, Schonauer V, Schneider B, Kyrle PA. Symptomatic pulmonary embolism and the risk of recurrent venous thromboembolism. Arch Intern Med. 2004;164:92-6.

37. Douketis JD, Kearon C, Bates S, Duku EK, Ginsberg JS. Risk of fatal pulmonary embolism in patients with treated venous thromboembolism. JAMA. 1998;279:458-62.

38. Tafur AJ, Wysokinski WE, McBane RD, Wolny E, Sutkowska E, Litin SC, Daniels PR, Slusser JP, Hodge DO, Heit JA. Cancer effect on periprocedural thromboembolism and bleeding in anticoagulated patients. Ann Oncol. 2012:23:1998-2005.

39. Douketis JD. Perioperative management of patients receiving anticoagulant or antiplatelet therapy: a clinician-oriented and practical approach. Hosp Pract. 2011;39:41-54

40. Cvirn G, Waha JE, Ledinski G, Schlagenhauf A, Leschnik B, Koestenberger M, Tafeit E, Hinghofer-Szalkay H, Goswami N. Bed rest does not induce hypercoagulability. Eur J Clin Investig. 2015;45:63-9.

41. Zhu W, He W, Guo L, Wang X, Hong K. The HAS-BLED score for predicting major bleeding risk in Anticoagulated patients with Atrial fibrillation: a systematic review and meta-analysis. Clin Cardiol. 2015;38:555-61.

42. O'Brien EC, Simon DN, Thomas LE, Hylek EM, Gersh BJ, Ansell JE, Kowey PR, Mahaffey KW, Chang P, Fonarow GC, et al. The ORBIT bleeding score: a simple bedside score to assess bleeding risk in atrial fibrillation. Eur Heart J. 2015:36:3258-64.

43. Hijazi Z, Oldgren J, Lindback J, Alexander JH, Connolly SJ, Eikelboom JW, Ezekowitz MD, Held C, Hylek EM, Lopes RD, et al. The novel biomarker-based $\mathrm{ABC}$ (age, biomarkers, clinical history)-bleeding risk score for patients with atrial fibrillation: a derivation and validation study. Lancet. 2016;387:2302-11.

44. Kirchhof P, Benussi S, Kotecha D, Ahlsson A, Atar D, Casadei B, Castella M, Diener HC, Heidbuchel H, Hendriks J, et al: 2016 ESC guidelines for the management of atrial fibrillation developed in collaboration with EACTS: the task force for the management of atrial fibrillation of the European Society 
of Cardiology (ESC)developed with the special contribution of the European heart Rhythm Association (EHRA) of the ESCEndorsed by the European stroke organisation (ESO). Eur Heart J 2016 Oct 7;37(38):2893-2962.

45. Heidbuchel $\mathrm{H}$, Verhamme P, Alings M, Antz M, Diener HC, Hacke W, Oldgren J, Sinnaeve P, Camm AJ, Kirchhof P, Advisors: Updated European heart Rhythm Association practical guide on the use of non-vitamin-K antagonist anticoagulants in patients with non-valvular atrial fibrillation: executive summary. Eur Heart J 2016. Jun 9. pii: ehw058.

46. Heidbuchel H, Verhamme P, Alings M, Antz M, Diener HC, Hacke W, Oldgren J, Sinnaeve P, Camm AJ, Kirchhof P, Advisors: Updated European heart Rhythm Association practical guide on the use of non-vitamin $\mathrm{K}$ antagonist anticoagulants in patients with non-valvular atrial fibrillation. Europace 2015. Oct;17(10):1467-1507.

47. Mauprivez C, Khonsari RH, Razouk O, Goudot P, Lesclous P, Descroix V. Management of dental extraction in patients undergoing anticoagulant oral direct treatment: a pilot study. Oral Surg Oral Med Oral Pathol Oral Radiol. 2016;122:e146-55.

48. Essebag V, Healey JS, Ayala-Paredes F, Kalfon E, Coutu B, Nery P, Verma A, Sapp J, Philippon F, Sandhu RK, et al. Strategy of continued vs interrupted novel oral anticoagulant at time of device surgery in patients with moderate to high risk of arterial thromboembolic events: the BRUISE CONTROL-2 trial. Am Heart J. 2016;173:102-7.

49. Madan S, Muthusamy P, Mowers KL, Elmouchi DA, Finta B, Gauri AJ, Woelfel AK, Fritz TD, Davis AT, Chalfoun NT. Safety of anticoagulation with uninterrupted warfarin vs. interrupted dabigatran in patients requiring an implantable cardiac device. Cardiovasc Diagn Ther. 2016;6:3-9.

50. Douxfils J, Lessire S, Dincq AS, Hjemdahl P, Ronquist-Nii Y, Pohanka A, Gourdin M, Chatelain B, Dogne JM, Mullier F. Estimation of dabigatran plasma concentrations in the perioperative setting. An ex vivo study using dedicated coagulation assays. Thromb Haemost. 2015;113:862-9.

51. Lessire S, Dincq AS, Douxfils J, Devalet B, Nicolas JB, Spinewine A, Larock AS, Dogne JM, Gourdin M, Mullier F. Preventive strategies against bleeding due to nonvitamin $\mathrm{K}$ antagonist oral anticoagulants. Biomed Res Int. 2014;2014:616405.

52. Pengo V, Crippa L, Falanga A, Finazzi G, Marongiu F, Palareti G, Poli D, Testa S, Tiraferri E, Tosetto A, et al. Questions and answers on the use of dabigatran and perspectives on the use of other new oral anticoagulants in patients with atrial fibrillation. A consensus document of the Italian Federation of Thrombosis Centers (FCSA). Thromb Haemost. 2011;106:868-76.

53. Jungbauer $L$, Dobias C, Stollberger C, Weidinger F. The frequency of prescription of P-glycoprotein-affecting drugs in atrial fibrillation. J Thromb Haemost. 2010;8:2069-70.

54. Douketis JD, Wang G, Chan N, Eikelboom JW, Syed S, Barty R, Moffat KA, Spencer FA, Blostein M, Schulman S. Effect of standardized Perioperative Dabigatran interruption on residual anticoagulation effect at the time of surgery or procedure. J Thromb Haemost. 2016 Jan;14(1):89-97.

55. Horlocker TT, Wedel DJ, Rowlingson JC, Enneking FK, Kopp SL, Benzon HT, Brown DL, Heit JA, Mulroy MF, Rosenquist RW, et al. Regional anesthesia in the patient receiving antithrombotic or thrombolytic therapy: American Society of Regional Anesthesia and Pain Medicine evidence-based guidelines (third edition). Reg Anesth Pain Med. 2010;35:64-101.

56. Cappelleri $G$, Fanelli A. Use of direct oral anticoagulants with regional anesthesia in orthopedic patients. J Clin Anesth. 2016;32:224-35.

57. Bateman BT, Mhyre JM, Ehrenfeld J, Kheterpal S, Abbey KR, Argalious M, Berman MF, Jacques PS, Levy W, Loeb RG, et al. The risk and outcomes of epidural hematomas after perioperative and obstetric epidural catheterization: a report from the multicenter Perioperative outcomes group research consortium. Anesth Analg. 2013;116:1380-5.

58. Moen V, Dahlgren N, Irestedt L. Severe neurological complications after central neuraxial blockades in Sweden 1990-1999. Anesthesiology. 2004;101:950-9.

59. Rosencher N, Bonnet MP, Sessler DI. Selected new antithrombotic agents and neuraxial anaesthesia for major orthopaedic surgery: management strategies. Anaesthesia. 2007;62:1154-60

60. Gogarten W, Vandermeulen E, Van Aken H, Kozek S, Llau JV, Samama CM. Regional anaesthesia and antithrombotic agents: recommendations of the European Society of Anaesthesiology. Eur J Anaesthesiol. 2010;27:999-1015.

61. Testa S, Tripodi A, Legnani C, Pengo V, Abbate R, Dellanoce C, Carraro P, Salomone L, Paniccia R, Paoletti O, et al. Plasma levels of direct oral anticoagulants in real life patients with atrial fibrillation: results observed in four anticoagulation clinics. Thromb Res. 2016;137:178-83.
62. Narouze S, Benzon HT, Provenzano DA, Buvanendran A, De Andres J, Deer TR, Rauck R, Huntoon MA: Interventional spine and pain procedures in patients on antiplatelet and anticoagulant medications: guidelines from the American Society of Regional Anesthesia and Pain Medicine, the European Society of Regional Anaesthesia and Pain Therapy, the American Academy of pain Medicine, the international Neuromodulation Society, the north American Neuromodulation Society, and the world Institute of Pain. Reg Anesth Pain Med 2015, 40:182-212.

63. Benzon HT, Avram MJ, Green D, Bonow RO. New oral anticoagulants and regional anaesthesia. Br J Anaesth. 2013;111(Suppl 1):i96-113.

64. Di Biase L, Burkhardt JD, Santangeli P, Mohanty P, Sanchez JE, Horton R, Gallinghouse GJ, Themistoclakis S, Rossillo A, Lakkireddy D, et al. Periprocedural stroke and bleeding complications in patients undergoing catheter ablation of atrial fibrillation with different anticoagulation management: results from the role of Coumadin in preventing Thromboembolism in Atrial fibrillation (AF) patients undergoing catheter ablation (COMPARE) randomized trial. Circulation. 2014;129:2638-44.

65. Lakkireddy D, Reddy YM, Di Biase L, Vallakati A, Mansour MC, Santangeli P, Gangireddy S, Swarup V, Chalhoub F, Atkins D, et al. Feasibility and safety of uninterrupted rivaroxaban for periprocedural anticoagulation in patients undergoing radiofrequency ablation for atrial fibrillation: results from a multicenter prospective registry. J Am Coll Cardiol. 2014;63:982-8.

66. Eitel C, Koch J, Sommer P, John S, Kircher S, Bollmann A, Arya A, Piorkowski C, Hindricks G. Novel oral anticoagulants in a real-world cohort of patients undergoing catheter ablation of atrial fibrillation. Europace. 2013;15:1587-93.

67. Nagao T, Inden Y, Shimano M, Fujita M, Yanagisawa S, Kato H, Ishikawa S, Miyoshi A, Okumura S, Ohguchi S, et al. Efficacy and safety of apixaban in the patients undergoing the ablation of atrial fibrillation. Pacing Clin Electrophysiol. 2015;38:155-63.

68. Nagao T, Inden Y, Shimano M, Fujita M, Yanagisawa S, Kato H, Ishikawa S, Miyoshi A, Okumura S, Ohguchi S, et al. Feasibility and safety of uninterrupted dabigatran therapy in patients undergoing ablation for atrial fibrillation. Intern Med. 2015;54:1167-73.

69. Cappato R, Marchlinski FE, Hohnloser SH, Naccarelli GV, Xiang J, Wilber DJ, Ma CS, Hess S, Wells DS, Juang G, et al. Uninterrupted rivaroxaban vs. uninterrupted vitamin $\mathrm{K}$ antagonists for catheter ablation in non-valvular atrial fibrillation. Eur Heart J. 2015;36:1805-11.

70. Nagao T, Inden Y, Yanagisawa S, Kato H, Ishikawa S, Okumura S, Mizutani Y, Ito T, Yamamoto T, Yoshida N, et al. Differences in activated clotting time among uninterrupted anticoagulants during the periprocedural period of atrial fibrillation ablation. Heart Rhythm. 2015;12:1972-8.

71. Konduru SV, Cheema AA, Jones P, Li Y, Ramza B, Wimmer AP. Differences in intraprocedural ACTs with standardized heparin dosing during catheter ablation for atrial fibrillation in patients treated with dabigatran vs. patients on uninterrupted warfarin. J Interv Card Electrophysiol. 2012;35:277-84. discussion 284

72. Efremidis M, Vlachos K, Letsas KP, Giannopoulos G, Lioni L, Georgopoulos S, Vadiaka M, Deftereos S, Sideris A. Low dose dabigatran versus uninterrupted acenocoumarol for peri-procedural anticoagulation in atrial fibrillation catheter ablation. J Electrocardiol. 2015;48:840-4.

73. Dincq AS, Lessire S, Chatelain B, Gourdin M, Dogne JM, Mullier F, Douxfils J. Impact of the direct oral anticoagulants on activated clotting time. J Cardiothorac Vasc Anesth. 2017 Feb;31(1):e24-7.

74. Kozek-Langenecker SA, Afshari A, Albaladejo P, Santullano CA, De Robertis E, Filipescu DC, Fries D, Gorlinger K, Haas T, Imberger G, et al. Management of severe perioperative bleeding: guidelines from the European Society of Anaesthesiology. Eur J Anaesthesiol. 2013;30:270-382.

75. Beyer-Westendorf J, Gelbricht V, Forster K, Ebertz F, Kohler C, Werth S, Kuhlisch E, Stange T, Thieme C, Daschkow K, Weiss N: Peri-interventional management of novel oral anticoagulants in daily care: results from the prospective Dresden NOAC registry. Eur Heart J 2014. Jul 21;35(28):1888-1896.

76. Steinberg BA, Peterson ED, Kim S, Thomas L, Gersh BJ, Fonarow GC Kowey PR, Mahaffey KW, Sherwood MW, Chang P, et al. Use and outcomes associated with bridging during anticoagulation interruptions in patients with atrial fibrillation: findings from the outcomes registry for better informed treatment of Atrial fibrillation (ORBIT-AF). Circulation. 2015;131:488-94.

77. Douketis JD, Healey JS, Brueckmann M, Eikelboom JW, Ezekowitz MD, Fraessdorf M, Noack H, Oldgren J, Reilly P, Spyropoulos AC, et al. 
Perioperative bridging anticoagulation during dabigatran or warfarin interruption among patients who had an elective surgery or procedure. Substudy of the RE-LY trial. Thromb Haemost. 2015;113:625-32.

78. Garcia D, Alexander JH, Wallentin L, Wojdyla DM, Thomas L, Hanna M, AlKhatib SM, Dorian P, Ansell J, Commerford P, et al. Management and clinical outcomes in patients treated with apixaban vs warfarin undergoing procedures. Blood. 2014;124:3692-8.

79. Garcia DA, Baglin TP, Weitz JI, Samama MM. American College of Chest P: Parenteral anticoagulants: antithrombotic therapy and prevention of thrombosis, 9th ed: American College of Chest physicians evidence-based clinical practice guidelines. Chest. 2012;141:e24S-43S.

80. Mar PL, Familtsev D, Ezekowitz MD, Lakkireddy D, Gopinathannair R. Periprocedural management of anticoagulation in patients taking novel oral anticoagulants: review of the literature and recommendations for specific populations and procedures. Int J Cardiol. 2016;202:578-85.

81. Flaker GC, Theriot P, Binder LG, Dobesh PP, Cuker A, Doherty JU. Management of Periprocedural Anticoagulation: a survey of contemporary practice. J Am Coll Cardiol. 2016;68:217-26.

82. Tafur AJ, McBane R 2nd, Wysokinski WE, Litin S, Daniels P, Slusser J, Hodge $D$, Beckman MG, Heit JA. Predictors of major bleeding in peri-procedural anticoagulation management. J Thromb Haemost. 2012;10:261-7.

83. Douxfils J, Mullier F, Dogne JM. Dose tailoring of dabigatran etexilate: obvious or excessive? Expert Opin Drug Saf. 2015;14:1283-9.

84. Martin K, Beyer-Westendorf J, Davidson BL, Huisman MV, Sandset PM, Moll S. Use of the direct oral anticoagulants in obese patients: guidance from the SSC of the ISTH. J Thromb Haemost. 2016;14:1308-13.

85. Testa S, Legnani C, Tripodi A, Paoletti O, Pengo V, Abbate R, Bassi L, Carraro P, Cini M, Paniccia R, et al: Poor comparability of coagulation screening test with specific measurement in patients on direct oral anticoagulants: results from a multicenter/multiplatform study. J Thromb Haemost 2016. Nov; 14(11):2194-2201.

86. Barrett $Y C$, Wang Z, Frost $C$, Shenker A. Clinical laboratory measurement of direct factor Xa inhibitors: anti-Xa assay is preferable to prothrombin time assay. Thromb Haemost. 2010;104:1263-71.

87. Gouin-Thibault I, Flaujac C, Delavenne X, Quenet S, Horellou MH, Laporte S, Siguret $\mathrm{V}$, Lecompte $\mathrm{T}$. Assessment of apixaban plasma levels by laboratory tests: suitability of three anti-Xa assays. A multicentre French GEHT study. Thromb Haemost. 2014;111:240-8.

88. Douxfils J, Chatelain C, Chatelain B, Dogne JM, Mullier F. Impact of apixaban on routine and specific coagulation assays: a practical laboratory guide. Thromb Haemost. 2013;110:283-94.

89. Cuker A, Siegal DM, Crowther MA, Garcia DA. Laboratory measurement of the anticoagulant activity of the non-vitamin K oral anticoagulants. J Am Coll Cardiol. 2014;64:1128-39.

90. Lessire S, Douxfils J, Baudar J, Bailly N, Dincq AS, Gourdin M, Dogne JM, Chatelain B, Mullier F. Is Thrombin Time useful for the assessment of dabigatran concentrations? An in vitro and ex vivo study. Thromb Res. 2015;136(3):693-6.

91. Douxfils J, Lessire S, Dincq AS, Hjemdahl P, Ronquist-Nii Y, Pohanka A, Gourdin M, Chatelain B, Dogne JM, Mullier F. Estimation of dabigatran plasma concentrations in the perioperative setting. An ex vivo study using dedicated coagulation assays. Thromb Haemost. 2014:113.

92. Mani H, Rohde G, Stratmann G, Hesse C, Herth N, Schwers S, Perzborn E, Lindhoff-Last E. Accurate determination of rivaroxaban levels requires different calibrator sets but not addition of antithrombin. Thromb Haemost. 2012;108:191-8.

93. Konigsbrugge O, Quehenberger P, Belik S, Weigel G, Seger C, Griesmacher A, Pabinger I, Ay C. Anti-coagulation assessment with prothrombin time and anti-Xa assays in real-world patients on treatment with rivaroxaban. Ann Hematol. 2015;94:1463-71.

94. Lessire S, Douxfils J, Pochet L, Dincq AS, Larock AS, Gourdin M, Dogné JM, Chatelain B, Mullier F. Estimation of rivaroxaban plasma concentrations in the perioperative setting in patients with or without heparin bridging. Clin Appl Thromb Hemost. 2016 Jan 1:1076029616675968; doi:10.1177/ 1076029616675968

95. Lessire S, Dincq AS, Douxfils J, Mullier F: Periprocedural management of direct oral anticoagulants should be guided by accurate laboratory tests. Reg Anesth Pain Med 2016 Nov/Dec;41(6):787-788.

96. Gosselin RC, Francart SJ, Hawes EM, Moll S, Dager WE, Adcock DM. Heparincalibrated Chromogenic anti-Xa activity measurements in patients receiving rivaroxaban: can this test be used to quantify drug level? Ann Pharmacother. 2015;49:777-83.
97. Douxfils J, Chatelain B, Hjemdahl P, Devalet B, Sennesael AL, Wallemaca P, Ronquist-Nii Y, Pohanka A, Dogne JM, Mullier F. Does the Russell viper venom time test provide a rapid estimation of the intensity of oral anticoagulation? A cohort study. Thromb Res. 2015 May; 135(5):852-60.

98. Exner T, Ellwood L, Rubie J, Barancewicz A. Testing for new oral anticoagulants with LA-resistant Russells viper venom reagents. An in vitro study. Thromb Haemost. 2013;109:762-5.

99. Altman R, Gonzalez CD. Simple and rapid assay for effect of the new oral anticoagulant (NOAC) rivaroxaban: preliminary results support further tests with all NOACs. Thromb J. 2014;12:7.

100. Altman R, Gonzalez CD. Supporting the use of a coagulometric method for rivaroxaban control: a hypothesis-generating study to define the safety cut-offs. Thromb J. 2015;13:26.

101. Dale BJ, Chan NC, Eikelboom JW. Laboratory measurement of the direct oral anticoagulants. Br J Haematol. 2016;172:315-36.

102. Pernod G, Albaladejo P, Godier A, Samama CM, Susen S, Gruel Y, Blais N, Fontana P, Cohen A, Llau JV, et al. Management of major bleeding complications and emergency surgery in patients on long-term treatment with direct oral anticoagulants, thrombin or factor-Xa inhibitors. Proposals of the Working group on Perioperative Haemostasis (GIHP) - march 2013. Ann Fr Anesth Reanim. 2013;32:691-700.

103. Godier A, Gouin-Thibault I, Rosencher N, Albaladejo P. Groupe d'Interet en Hemostase P: [management of direct oral anticoagulants for invasive procedures]. J Mal Vasc. 2015;40:173-81.

104. Grottke O, Aisenberg J, Bernstein R, Goldstein P, Huisman MV, Jamieson DG, Levy JH, Pollack CV Jr, Spyropoulos AC, Steiner T, et al. Efficacy of prothrombin complex concentrates for the emergency reversal of dabigatran-induced anticoagulation. Crit Care. 2016;20:115.

105. Lohrmann GM, Atwal D, Augoustides JG, Askar W, Patel PA, Ghadimi K, Makar G, Gutsche JT, Shamoun FE, Ramakrishna H. Reversal agents for the new generation of oral anticoagulants: implications for the Perioperative physician. J Cardiothorac Vasc Anesth. 2016;30:823-30.

106. Chai-Adisaksopha C, Hillis C, Lim W, Boonyawat K, Moffat K, Crowther M. Hemodialysis for the treatment of dabigatran-associated bleeding: a case report and systematic review. J Thromb Haemost. 2015;13:1790-8.

107. Schulman S, Ritchie B, Nahirniak S, Gross PL, Carrier M, Majeed A, Hwang HG, Zondag M. Study i: reversal of dabigatran-associated major bleeding with activated prothrombin concentrate: a prospective cohort study. Thromb Res. 2017;152:44-8.

108. Schiele F, van Ryn J, Canada K, Newsome C, Sepulveda E, Park J, Nar H, Litzenburger T. A specific antidote for dabigatran: functional and structural characterization. Blood. 2013;121:3554-62.

109. Glund S, Stangier J, Schmohl M, Gansser D, Norris S, van Ryn J, Lang B, Ramael S, Moschetti V, Gruenenfelder F, et al. Safety, tolerability, and efficacy of idarucizumab for the reversal of the anticoagulant effect of dabigatran in healthy male volunteers: a randomised, placebo-controlled, double-blind phase 1 trial. Lancet. 2015;386:680-90.

110. Glund S, Moschetti V, Norris S, Stangier J, Schmohl M, van Ryn J, Lang B, Ramael $S$, Reilly P. A randomised study in healthy volunteers to investigate the safety, tolerability and pharmacokinetics of idarucizumab, a specific antidote to dabigatran. Thromb Haemost. 2015;113:943-51.

111. Schmohl M, Glund S, Harada A, Imazu S, De Smet M, Moschetti V, Ramael S, Ikushima I, Grunenfelder F, Reilly P, Stangier J. Idarucizumab does not have procoagulant effects: assessment of thrombosis biomarkers in healthy volunteers. Thromb Haemost. 2017;117:269-76.

112. Pollack CV Jr, Reilly PA, Eikelboom J, Glund S, Verhamme P, Bernstein RA, Dubiel R, Huisman MV, Hylek EM, Kamphuisen PW, et al. Idarucizumab for Dabigatran Reversal. N Engl J Med. 2015;373:511-20.

113. Pollack CV, Reilly PA, van Ryn J, Eikelboom J, Glund S, Bernstein RA, Dubiel R, Huisman MV, Hylek EM, Kamphuisen PW, et al. Idarucizumab for Dabigatran Reversal: Updated Results of the RE-VERSE AD Study. In American Heart Association Scientific Sessions 2016. New Orleans: The American Journal of Managed Care; 2016. http://www.ajmc.com/ conferences/aha2016/results-of-the-re-verse-ad-study-confirmidacizumabefficacy-safety-at-follow-up.

114. Siegal DM, Curnutte JT, Connolly SJ, Lu G, Conley PB, Wiens BL, Mathur VS, Castillo J, Bronson MD, Leeds JM, et al. Andexanet Alfa for the reversal of factor Xa inhibitor activity. N Engl J Med. 2015;373:2413-24.

115. Connors JM. Antidote for Factor Xa Anticoagulants. N Engl J Med. 2015;373:2471-2. 
116. Ansell JE, Bakhru SH, Laulicht BE, Steiner SS, Grosso M, Brown K, Dishy V, Noveck RJ, Costin JC. Use of PER977 to reverse the anticoagulant effect of edoxaban. N Engl J Med. 2014;371:2141-2.

117. Ansell JE, Bakhru SH, Laulicht BE, Steiner SS, Grosso MA, Brown K, Dishy V, Lanz HJ, Mercuri MF, Noveck RJ, Costin JC. Single-dose ciraparantag safely and completely reverses anticoagulant effects of edoxaban. Thromb Haemost. 2017;117:238-45.

118. Khadzhynov D, Wagner F, Formella S, Wiegert E, Moschetti V, Slowinski T, Neumayer HH, Liesenfeld KH, Lehr T, Hartter S, et al. Effective elimination of dabigatran by haemodialysis. A phase I single-centre study in patients with end-stage renal disease. Thromb Haemost. 2013;109:596-605.

119. Connolly SJ, Milling TJ Jr, Eikelboom JW, Gibson CM, Curnutte JT, Gold A, Bronson MD, Lu G, Conley PB, Verhamme P, et al. Andexanet Alfa for acute major bleeding associated with factor Xa inhibitors. N Engl J Med. 2016:375:1131-41.

120. Greinacher A, Thiele T, Selleng K. Reversal of anticoagulants: an overview of current developments. Thromb Haemost. 2015;113:931-42.

121. Rottenstreich A, Jahshan N, Avraham L, Kalish Y. Idarucizumab for dabigatran reversal - does one dose fit all? Thromb Res. 2016;146:103-4.

\section{Submit your next manuscript to BioMed Central} and we will help you at every step:

- We accept pre-submission inquiries

- Our selector tool helps you to find the most relevant journal

- We provide round the clock customer support

- Convenient online submission

- Thorough peer review

- Inclusion in PubMed and all major indexing services

- Maximum visibility for your research

Submit your manuscript at www.biomedcentral.com/submit 